\title{
Penerapan Tema Metafora dalam Perencanaan Pasar Ikan Modern di Kabupaten Sidoarjo
}

\author{
Indah Dwi Setyowati ${ }^{1}$, Narewarananindya $^{2}$, Ika Ratniarsih ${ }^{3}$ \\ 1,2,3 Jurusan Arsitektur, Fakultas Teknik Sipil dan Perancangan, Institut Teknologi Adhi Tama Surabaya, \\ Surabaya, Indonesia \\ Email: $\underline{\text { indahdwi166@gmail.com }}$
}

\begin{abstract}
Sidoarjo Regency is an area located in East Java Province, one of the fish producers. With the main livelihood as a fisherman. This potential makes the Sidoarjo area one of the minapolitan areas in Indonesia. The Modern Fish Market is located on Jalan K.H. Ali Mas'ud, Sidokerto Village, Buduran District, Sidoarjo. It consists of several facilities, namely the main facility as a point of sale, management facilities as an office, supporting facilities, service facilities, and a cafeteria. The use of the Modern Hygienic macro concept produces a design that has a clean, modern and efficient atmosphere so that visitors do not get bored of making transactions in the Market area.
\end{abstract}

Keywords: modern fish market, methaporical architecture

\begin{abstract}
Abstrak. Di Kabupaten Sidoarjo merupakan daerah yang berada di Provinsi Jawa Timur salah satu penghasil ikan. Dengan mata pencaharian utama sebagai nelayan. Potensi tersebut menjadikan daerah Sidoarjo sebagai salah satu Kawasan minapolitan di Indonesia. Pasar Ikan Modern berada di Jalan K.H. Ali Mas'ud, Desa Sidokerto, Kecamatan Buduran, Sidoarjo. Terdiri dari beberapa fasilitas, yaitu fasilitas utama sebagai tempat penjualan, fasilitas pengelola sebagai kantor, fasilitas penunjang, fasilitas servis, dan cafeteria. Penggunaan konsep makro Modern Higenis menghasilkan rancangan yang memiliki suasana yang bersih, modern dan efisien sehingga pengunjung tidak bosan bertransaksi di area Pasar.
\end{abstract}

Kata Kunci: pasar ikan modern, arsitektur metafora

\section{Pendahuluan}

Perencanaan dan Perancangan Pasar Ikan Modern di Sidoarjo ini proses merancang suatu Pasar Ikan yang bersifat modern dengan memperbaiki fasilitas serta kesan masyarakat terhadap pasar pada umumnya. Yang dimana di dalamnya mempunyai kurang lebih 150 pedagang yaitu, Pedagang Ikan segar, Pedagang Ikan olahan, serta Pedagang kuliner. Dengan ini selain memajuka Perikanan Indonesia juga membantu memajukan perekonomian UMKM/masyarakat sekitar. Perbedaan Pasar Ikan Modern dan Pasar Ikan Konvensional pada umumnya mempunyai 6 perbedaan mulai dari kondisi produk, harga produk, solidaritas antar penjual, kebersihan dan fasilitas, sistem jual beli, dan jam buka pasar.

Menurut (Pemerintah Sidoarjo, 1859) Kabupaten Sidoarjo merupakan salah satu kota ikan yang dimana sebagai penghasil ikan, salah satunya ikan bandeng terutama di provinsi Jawa Timur. Sidoarjo dikenal dengan lambang udang dan bandeng, yang dulunya Kota Sidoarjo ini di kelilingi lautan sehingga sampai saat ini Kota ini menjadi asri dan indah. Kawasan Sidoarjo merupakan penghasil ikan di Provinsi Jawa Timur, Menjadikan Iconic Pusat perbelanjaan boga bahari di Jawa Timur. Di Kota Sidoarjo banyak pasar ikan yang belum menerapkan tata zona yang sesuai dan fasilitas yang memadahi. Itulah yang menjadi alasan perlunya wacana pembangunan pasar ikan, berupa Perancangan Pasar Ikan Modern.

Perencanaan Pasar Ikan Modern ini diharapkan dapat menjadi tempat perbelanjaan boga bahari yang memiliki fasilitas yang sesuai dan memberikan kenyamanan serta keamanan saat bertransaksi. Dengan berwawasan lingkungan yang memanfaatkan potensi lingkungan yang ada. Dengan demikian pengunjung dapat merasakan serta menikmati pasar modern ini dengan nyaman dan aman.

\subsection{Tema Arsitektur Metafora}

Mengutip pemahaman dari Charles Jenks dalam bukunya "The Language of Post Modern Achitecture", Arsitektur dikaitkan dengan gaya bahasa, antara lain dengan cara metafora. Pengertian Metafora dalam Arsitektur adalah kiasan atau ungkapan bentuk, diwujudkan dalam bangunan dengan harapan akan menimbulkan tanggapan dari orang yang menikmati atau memakai karyanya. Metafora 
atau kiasan pada dasarnya mirip dengan konsep analogi dalam arsitektur, yaitu menghubungkan di antara benda-benda.

Mengutip jurnal (Arsitektur Metafora, 2016) Metafora merupakan bagian dari gaya bahasa yang digunakan untuk menjelaskan sesuatu melalui persamaan dan perbandingan. Metafora berasal dari bahasa latin yaitu "Methapherein" yang terdiri dari 2 buah kata yaitu "metha" yang berarti : setelah, melewati dan "pherein" yang berarti : membawa. Secara etimologis diartikan sebagai pemakaian katakata bukan arti sebenarnya, melainkan sebagai lukisan yang berdasarkan persamaan dan perbandingan. Pada awal tahun 1970-an muncul ide untuk mengkaitkan arsitektur dengan bahasa. Estimologis ialah suatu cabang ilmu linguistik atau ilmu bahasa (yang mengkaji bahasa ini juga bersifat terbuka terhadap pengaruh dan kedekatan dengan ilmu lain), atau mempelajari tentang bahasa kuno yang merupakan "generasi yang lebih lama" maka dari itu akar bahasa yang telah diketahui dapat ditelusuri jauh ke belakang kepada asal usul keluarga bahasa Austronesia. Metafora mengidentifikasi hubungan benda, dimana hubungan benda tersebut lebih bersifat abstrak dari pada hubungan sejajar. Karya Arsitektur menggunakan metoda rancang metafora, hasil kaya arsitek terkenal cederung mempunyai langgam Postmodern.

\subsection{Aspek-Aspek Desain Metafora}

Mengutip jurnal (Sapti, 2016) Ditinjau dari mengidentifikasi penerapan bertema Metafora arsitektur ke dalam 3 kategori, yakni: a) Metafora tak teraba (intangible metaphore) yaitu memetaforakan sesuatu yang tidak dimunculkan dalam bentuk arsitekturnya melainkan diwujudkan dalam konsep, ide, sebagian kondisi atau sebagian karakter. b) Metafora teraba (tangible metaphor) yaitu memetaforakan sesuatu yang dimunculkan secara langsung dalam bentuk arsitekturnya atau materialnya. c) Metafora kombinasi (combined metaphor) yakni metafora yang merupakan gabungan antara metafora langsung dan tidak langsung, baik melalui konsep, ide, persepsi, atau bentuk.

Dengan tema "Metafora" maka yang harus menjadi penekanan utama adalah penerapan bentuk bangunan yang dianalogikan dari suatu bentuk tertentu, baik secara makna maupun visual.. Pada pasar ini mengutamakan kanyamanan terutama di lingkungan pusat jual beli, karna tingkat aktivitas lebih banyak.

Mengutip dari jurnal (Azzahra, 2011) Perencanaan adalah proses mendefinisikan tujuan organisasi, membuat strategi untukmencapai tujuan itu, dan mengembangkan rencana aktivitas kerja organisasi. Rencanadapat berupa rencana informal atau rencana formal. Rencana informal adalah rencanayang tidak tertulis dan bukan merupakan tujuan bersama anggota suatu organisasi. Perancangan adalah Proses, cara, perbuatan merancang sebelum bertindak, mengerjakan, atau melakukan suatu pekerjaan. Proses perancangan harus disusun dengan permikiran dan pertimbangan yang matang, agar hasil yang dicapai memuaskandan dapat memenuhi kebutuhan yang ingin di capai.

Pasar Ikan adalah sekumpulan pembeli dan penjual dari sebuah barang atau jasa berupa ikan segar ataupun boga bahari. Para pembeli sebagai sebuah kelompok yang menentukan permintaan terhadap produk dan para penjual sebagai kelompok yang menentukan penawaran terhadap produk. Modern adalah merujuk sesuatu yang "terkini" atau terbaru seiring mengikuti perkembangan zaman. Kabupaten Sidoarjo adalah sebuah kota di Provinsi Jawa Timur, Indonesia. Kota Sidoarjo sebagai salah satu penyangga Ibu kota Provinsi Jawa Timur merupakan daerah yang mengalami perkembangan pesat karena memiliki berbagai potensi yang ada di wilayahnya seperti industri dan perdagangan, pariwisata, serta usaha kecil dan menengah dapat dikemas dengan baik dan terarah. Dengan adanya berbagai potensi daerah serta dukungan sumber daya manusia yang memadai, maka dalam perkembangannya Kota Sidoarjo mampu menjadi salah satu daerah strategis bagi pengembangan perekonomian regional. Kota Sidoarjo terletak antara $112^{\circ} 5^{\prime}$ dan $112^{\circ} 9^{\prime}$ Bujur Timur dan antara $7^{\circ} 3^{\prime}$ dan $7^{\circ} 5^{\prime}$ Lintang Selatan.

\subsection{Ciri - Ciri Pasar Modern}

Ciri-ciri pasar modern sesuai dengan Peraturan Direktorat Jenderal Kelautan (PDSPKP, 2013) adalah sebagai berikut: (a) Tidak ada sistem tawar menawar antara penjual dan pembeli. Penjual sudah menetapkan harga yang sudah tertera pada ikan yang dijual, sehingga membutuhkan ruang sirkulasi berupa ruang pendestrian dengan lebar yang cukup sehingga dapat beraktivitas dengan nyaman; dan (b) 
Pedagang di pasar modern berjumlah lebih dari satu sehingga terdapat satu manajemen seperti yang sudah di tetapkan oleh pihak pengelola.

Ciri pasar berdasarkan pengelompokan dan jenis barang pasar, yakni: jenis barang di pasar umumnya dibagi dalam empat kategori: (a) Kelompok bersih (kelompok jasa, kelompok warung, toko); (b) Kelompok kotor yang tidak bau (kelompok hasil bumi dan buah-buahan); (c) Kelompok kotor yang bau dan basah (kelompok sayur dan bumbu); dan (d) Kelompok bau, basah, kotor, dan busuk (kelompok ikan basah dan daging).

Wujud tempat berjualan juga dapat menjadi identitas dari pasar modern. Tempat berjualan atau lebih sering disebut stan, dipilih dengan cara undian (stan yang ada adalah stan milik sendiri dengan membayar biaya retribusi per $\mathrm{m}^{2} /$ hari sesuai dengan biaya yang telah ditetapkan). Jenis barang yang telah dikelompokkan, dilihat jenis barang dagangan apayang paling banyak diperdagangkan dan paling diminati. Bagian atau blok-blok yang telah di tetapkan tempat-tempat yang strategis diutamakan diundi dahulu untuk pengurus setiap bagian, setelah itusisanya diundi untuk pedagang lainnya.

Tempat-tempat yang strategis selalu diminati oleh pedagang, karena terlebih dahulu terlihat atau dikunjungi oleh pembeli. Tempat staregis yang dimaksud adalah sirkulasi utama, dekat pintu masuk, dekat tangga, atau dekat hall.

Beberapa tipe tempat berjualan, antara lain:

(1) Kios, Merupakan tipe tempat berjualan yang tertutup, tingkat keamanan lebih tinggi dibanding dengan yang lain. Dalam kiosdapat ditata dengan berbagai macam alat display. Pemilikan kios, tidak hanya satu saja tetapi dapat beberapa kios sesuai dengankebutuhan yang diinginkan.

(2) Los, Merupakan tipe tempat berjualan yang terbuka, tetapi telah dibatasi secara pasti (dibatasi dengan barang-barang yang sukar bergerak, misalnya lemari, meja, kursi, dan sebagainya) atau bersifat tetap.

(3) Oprokan / Pelataran, Merupakan tipe tempat berjualan yang terbuka atau tidak dibatasi secara tetap. Tetapi mempunyai tempatnya sendiri. Yangtermaksud pedagang oprokan di pasar adalah pedagang asonganyang berjualan di dalam pasar maupun yang di luar pasar tetapimasih menempel di dinding pasar.

\subsection{Syarat - syarat Pasar Modern}

Adapun syarat yang mengatur mengenai pasar modern, sesuai dengan (Peraturan Presiden RI No. 112, 2007), tentang penataan dan pembinaan pasar tradisional pusat perbelanjaan dan toko modern, yaitu:

(1) Aksebilitas, yaitu kemungkinan pencapaian dari dan ke kawasan, dalam kenyataan ini bewujud jalan dan transportasi atau pengaturan lalu lintas.

(2) Kompatibilitas, yaitu keserasian dan keterpaduan antara kawasan yang menjadi lingkungannya.

(3) Fleksibilitas, yaitu kemungkinan pertumbuhan fisik atau pemekaran kawasan pasar dikaitkan dengan kondisi fisik lingkungan dan keterpaduan prasarana.

(4) Ekologis, yaitu keterpaduan antara tatanan alam yang mewadahinya.

\subsection{Syarat - syarat Perdagangan ikan di Pasar Ikan}

Menurut (SNI, 2013) pengembangan sektor perikanan harus bersinergi dalam mewujudkan produk perikanan yang berkualitas, yang mampu bersaing dengan produk yang di hasilkan oleh negara lain. Syarat ini menetapkan syarat mutu dan keamanan pangan ikan segar, bahan baku, dan penanganan ikan segar.

\section{Metodologi}

Metode yang digunakan dalam penelitian ini adalah penelitian deskriptif mengenai beberapa bangunan yang dijadikan sebagai obyek studi banding. Studi banding ini terdiri dari studi lapangan dan studi literature mengenai obyek yang berkaitan dengan Perencanaan dan Perancangan Pasar Ikan Modern di Kota Sidoarjo. Studi banding literatur pada pasar modern ini terletak pada bangunan, ruang, dan tatanan lahan pada pasar tersebut.

\subsection{Studi Kasus Penelitian}


Studi kasus dilakukan untuk mengetahui mengenai desain yang akan direncenakan. Hal ini tidak lain, agar dalam perencanaan bangunan Pasar Modern ini memiliki arah yang jelas serta memperkaya ide desain.

Tabel 1. Studi kasus berdasarkan tema metafora agar seseorang dapat memahami karakteristik serta prinsip pada pasar tersebut dengan menganalogikan suatu objek.

\begin{tabular}{lll}
\hline Nama Objek & Kelebihan & Kelemahan \\
\hline Museum Tsunami Aceh & $\begin{array}{l}\text { Mengambil dari fungsi bangunan dengan } \\
\text { bentuk metafora dari gelombang tsunami. }\end{array}$ & Area terbatas, karena minim lahan. \\
\hline Pavilion Luxembourg & $\begin{array}{l}\text { Memanfaatkan lahan minimalis untuk } \\
\text { sebuah pavilion dengan menganalogikan } \\
\text { sebuah pita. }\end{array}$ & \\
\hline Sydney Fish Market & $\begin{array}{l}\text { Mempunyai kapasitas yang besar untuk } \\
\text { sebuah pasar ikan modern. }\end{array}$ & Area terbatas \\
\hline Fishterra Fish Market & Lokasi strategis dengan singgah kapal & \\
\hline
\end{tabular}

\subsection{Pemilihan Lokasi dan Analisa Site}

Daerah Sidoarjo merupakan area yang sangat berpotensi untuk wilayah perindustrian, perdagangan dan pariwisata, serta usaha kecil yang sangat berkembang pesat. Site dipilih di Jl. K.H.Mukmin karena daerah tersebut merupakan daerah komersil dan merupakan pusat kota. Sehingga masyarakat dapat mudah mengakses ke daerah Pasar tersebut.
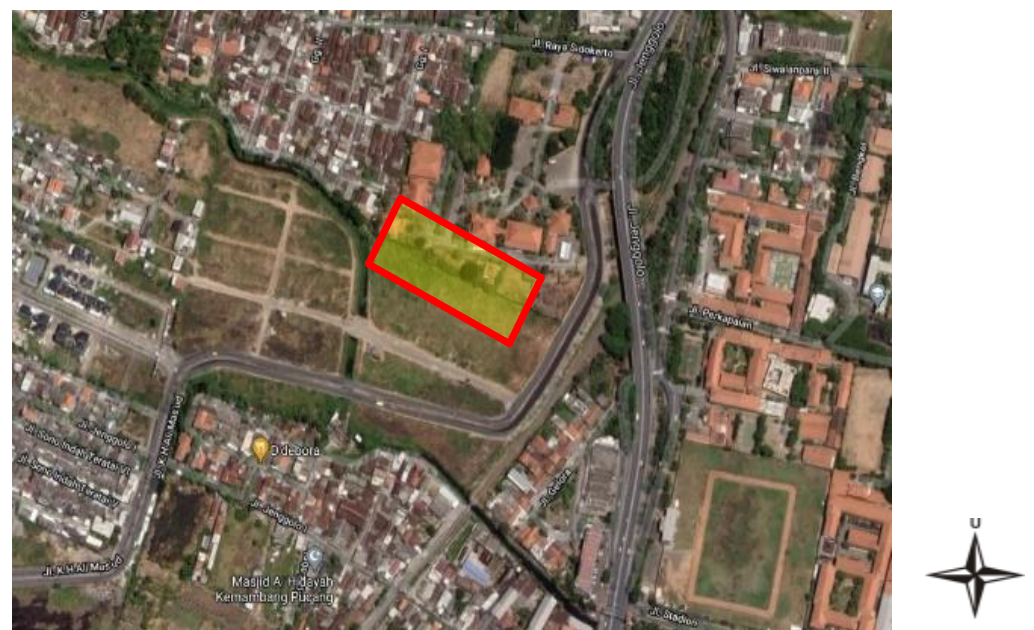

Gambar 1. Site

Sumber: Citra Google Maps, 2020

Adapun batas-batas site terpilih antara lain: sisi Utara: Lahan Kosong yang berbatasan langsung dengan Museum MPU Tantular dan Permukiman; sisi Timur: Berbatasan langsung dengan Jalan Utama K.H. Ali Mas'ud; sisi Barat: Perumahan Warga; sisi Selatan: Lahan kosong yang berbatasan langsung dengan Jalan Utama K.H. Ali Mas'ud.

Berdasarkan hasil beberapa kajian tentang analisa site yang dapat disimpulkan beberapa pertimbangan dalam proses Perencanaan dan Perancangan Pasar Ikan Modern di Kota Sidoarjo, yaitu: Analisa Klimatologi (Cahaya Matahari), penataan banyak massa dan vegetasi yang baik dapat meminimalisir panas cahaya matahari yang berlebih. Selain itu dapat menggunakan secondary skin yang berguna sebagai nilai tambah estetika bangunan.

Analisa Klimatologi (Arah Angin dan Curah Hujan), penataan banyak massa dan vegetasi yang baik dapat meminimalisir kecepatan angin dan dapat mengarahkan angin menuju tiap sudut bangunan di dalam lahan. Vegetasi pada lahan juga dapat menyaring debu yang dibawa angin.

Analisa Kondisi Visual (Orientasi), Perencanaan dan Perancangan Pasar Ikan Modern menggunakan orientasi ke dalam. Hal ini disebabkan oleh kurangnya view yang menarik yang ada di sekitar site. 
Analisa Kondisi Visual (Kebisingan), potensi kebisingan yang ada pada sisi timur lahan dapat diminamilisir dengan cara member jarak dari batas site serta menggunakan vegetasi di sekitar batas site yang dapaat berfungsi sebagai peredam yang berasal dari jalan utama.

Kajian Main Entrance (ME) \& Side Entrance (SE), meninterpretasikan mengenai penempatan pintu masuk utama diletakkan pada sisi area jalan utama dan pintu penunjang diletakkan pada sisi barat site. Kajian analisa View, dapat disimpulkan bahwa penataan bangunan yang lebih menonjol dapat diletakkan pada posisi yang strategis dapat terlihat dengan mudah oleh pengguna jalan.

\subsection{Program ruang}

Program ruang pada Pasar Ikan Modern ini ada beberapa bangunan yaitu Stand ikan kering, stand ikan basar, stand ikan hidup, fasilitas penunjang seperti mushola dan cafeteria. Dengan memiliki ruangan yang higenis, efisien, serta nyaman terhadap pengguna.

Tabel 2. Fasilitas Pasar ikan modern

\begin{tabular}{ll}
\hline Fasilitas & Luas Ruang \\
\hline Fasilitas stand ikan kering & $2.395 \mathrm{~m}^{2}$ \\
\hline Fasilitas stand ikan basah & $2.337 \mathrm{~m}^{2}$ \\
\hline Fasilitas stand ikan hidup \& R. Staff & $1.693 \mathrm{~m}^{2}$ \\
\hline Fasilitas pelanggan dan mushola & $831 \mathrm{~m}^{2}$ \\
\hline Fasilitas souvenir dan cafetaria & $3.130 \mathrm{~m}^{2}$ \\
\hline
\end{tabular}

\section{Hasil dan pembahasan}

Pada pasar ikan modern ini suatu proses merancang bangunan yang bersifat modern dengan memperbaiki fasilitas dan citra pasar ikan di kalangan masyarakat. Dengan memiliki 200 stand pedagang. Perbedaan pada pasar ini terletak pada sistematis struktur sirkulasi area serta fasilitas yang di tawarkan di area tersebut, mulai dari kondisi produk, harga produk, kebersihan area stand, system operasional dan system transaksi.

Tatanan lahan pada pasar ikan ini yaitu terpusat di mana salah satu bangunan sebagai poros dari bangunan lain dengan menggunakan sirkulasi radial, agar pengunjung dapat menikmati suasana yang ada di area tersebut. Berikut adalah salah satu konsep tatanan lahan dari pasar ikan tersebut

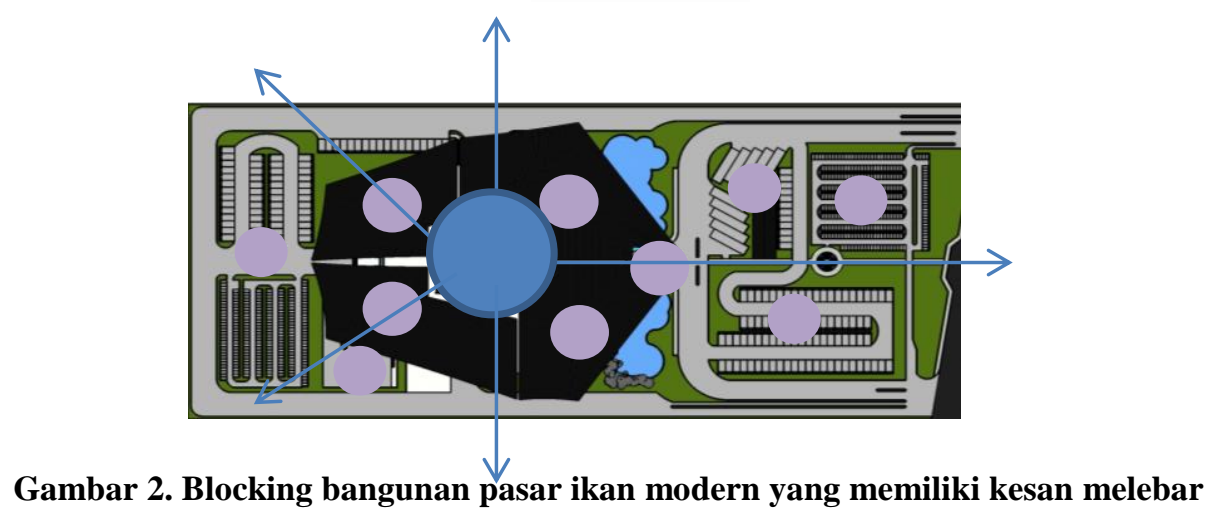

Ikan pari menjadi objek metafora pada bangunan ini dengan karakteristik ikan yang lebar serta kuat. Ruangan yang ada di dalamnya direncanakan untuk memiliki desain yang bersih, higenis serta ramah terhadap pengguna. Dari segi stuktur, bangunan Pasar Ikan ini didesain untuk memiliki struktur yang kuat tahan lama dan nyaman serta aman bagi siapapun yang beraktivitas di dalamnya. 


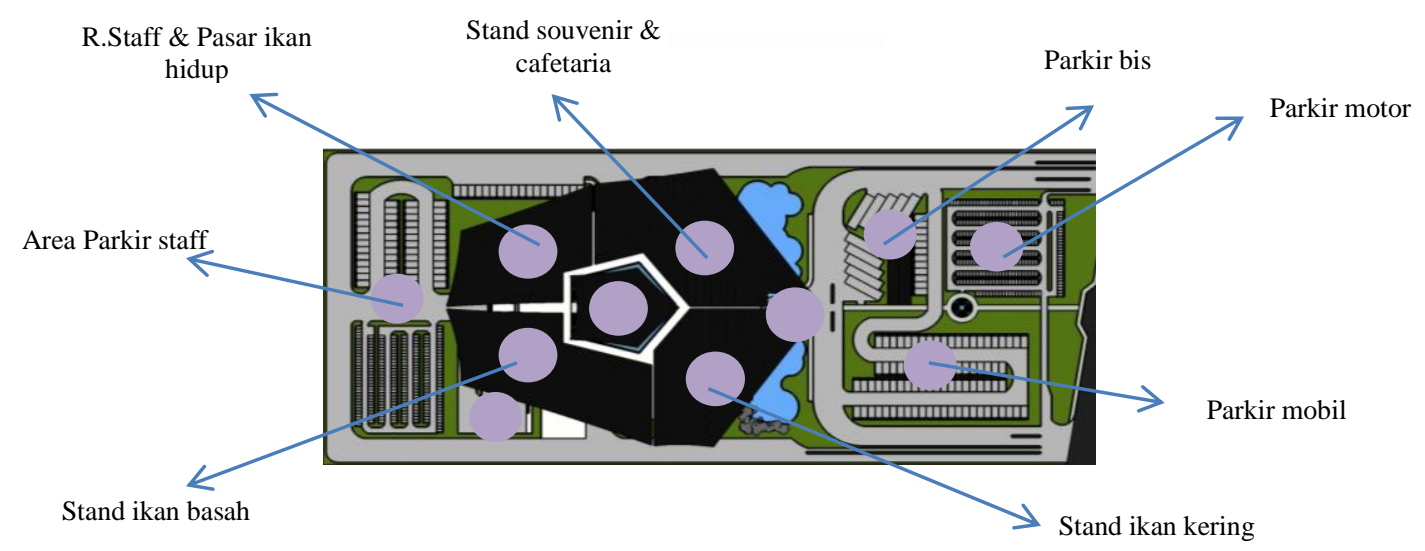

\section{Gambar 3. Block plan}

Gambar 3, menunjukkan bahwa block plan dibuat radial/ menyebar untuk memperkuat kesan lebar dari badan ikan pari.

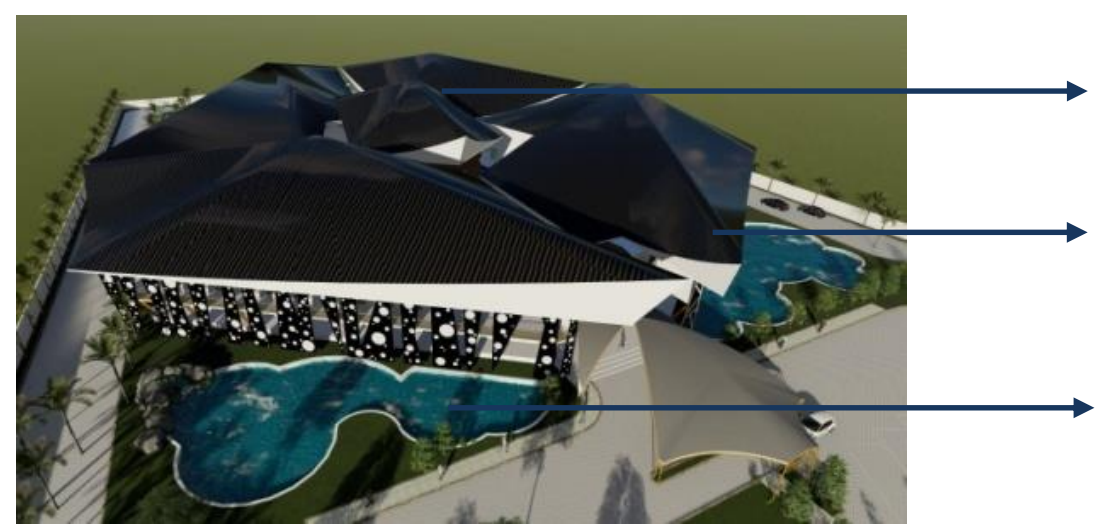

Gambar 4. Prespektif Area Pasar Ikan
Bangunan pelelangan ikan sebagai poros dari bangunan lain. View mata burung memperlihatkan secara keseluruhan bentuk pasar ikan modern.

Penanaman vegetasi yang maksimal menjadikan bangunan tampak asri dan higenis.
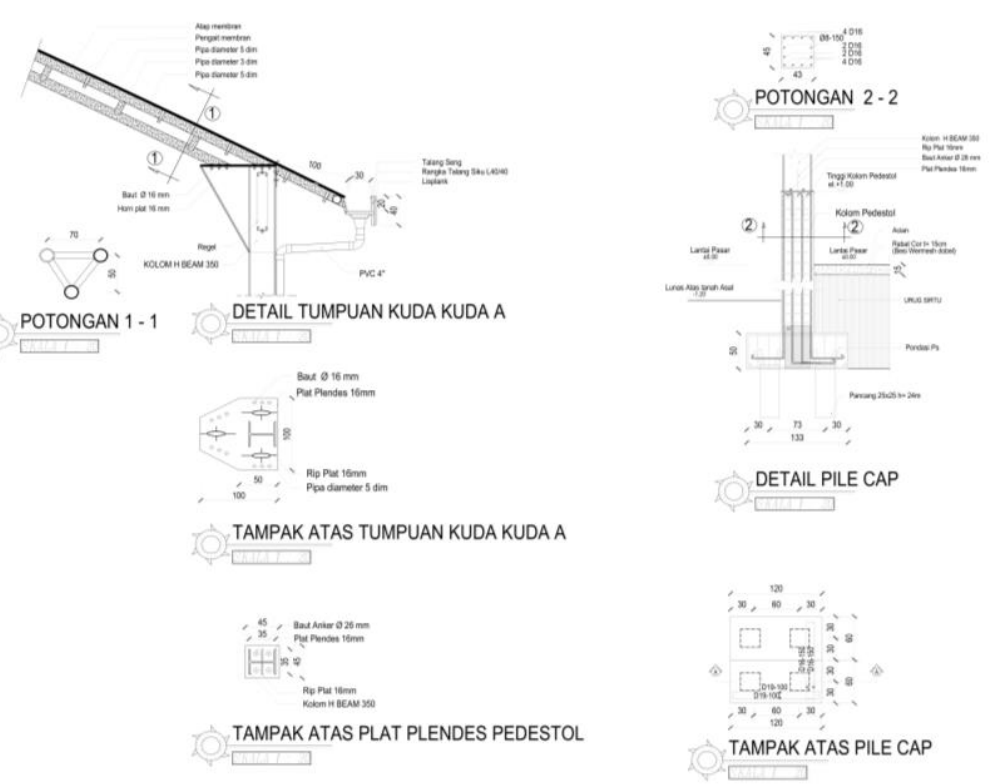

Gambar 5. Detail struktur pasr ikan 
Pada pasar ikan menggunakan struktur rangka atap baja dan material atap menggunakan atap membran ACP (Alumunium Composite Panel). Sehingga membuat atap pasar lebih kokoh dengan berat lebih ringan tetapi kekuatan yang cukup tahan karat. Karakter ACP cocok untuk diterapkan pada permukaan-permukaan yang lebar. Hal inilah yang diadopsi dalam perencanaan pasar ikan modern di Kabupaten Sidoarjo.

\section{Kesimpulan}

Pasar ikan modern ini adalah suatu wadah jual beli barang dibidang boga bahari yang memberikan fasilitas modern yaitu, area stand ikan kering, ikan basah, tempat pelelangan ikan, area stand ikan hidup serta cafeteria dan souvenir. Mengunsung konsep higenis memberikan kenyamanan saat pengunjung datang di area tersebut. Penerapan arsitektur metafora mampu mempresentasikan suatu objek dalam bentuk bangunan. Adanya pasar ini memancing peningkatan minat masyarakat untuk berbelanja di pasar ikan, serta memajukan perkenomian masyarakat setempat. Penerapan arsitektur metafora mampu mempresentasikan ikan pari sebagai salah satu hasil bahari yang diminati oleh pembeli di pasar ikan, ke dalam bentuk bangunan yang berfungsi sebagai pasar ikan modern di Sidoarjo.

\section{Referensi}

Arsitektur Metafora. (2016). Konsep Arsitektur Metafora. 20 November 2016, 4(1), 422-431. http://arsitekturmetafora.blogspot.com/

Azzahra. (2011). Perencanaan dan Perancangan Pasar ikan modern di Palembang. https://repository.unsri.ac.id/35383/

PDSPKP, peraturan direktur jendral. (2013). Peraturan Direktorat Jenderal Kelautan. Journal of Chemical Information and Modeling, 53(9), 1689-1699.

Pemerintah Sidoarjo. (1859). Pemerintahan kabupaen Sidoarjo. https://www.sidoarjokab.go.id/kabupaten-sidoarjo

Peraturan Presiden RI No. 112. (2007). Peraturan Presiden RI No. 112 Tahun 2007 Tentang Penataan Dan Pembinaan Pasar Tradisional, Pusat Perbelanjaan Dan Toko Modern. Peraturan Presiden Republik Indonesia, 1, 22. https://peraturan.bpk.go.id/Home/Details/42157/perpres-no-112tahun-2007

Sapti, M. (2016). Aspek-aspek perancangan arsitektur dan implementasinya. Kemampuan Koneksi Matematis (Tinjauan Terhadap Pendekatan Pembelajaran Savi), 53(9), 1689-1699.

SNI. (2013). SNI 2729:2013 Ikan Segar. Badan Standarisasi Nasional, 1-15. 


\section{Halaman ini sengaja dikosongkan}

